1,322 - 6,26; $p=0,00)$; và EF thấp hơn (HR cho mối $1 \%$ EF thấp hơn =1,10; KTC95\%: 1,04 $1,21 ; p=0,013)$.

Phân tích hồi quy Cox đa biến cho thây: KCĐB6P<290m(HR hiệu chỉnh=2,55; KTC95\%: $1,05$ - 6,23; $p=0,039)$, nồng độ NT- proBNP > 655(HR hiệu chỉnh=2,05; KTC95\%: 1,04 - 5,30; $\mathrm{p}=0,044)$, và EF thấp hơn (HR hiệu chỉnh cho mỗi 1\% EF thấp hơn=1,07; KTC95\%: 1,02 $1,19 ; p=0,045)$ là những yếu tố tiên lượng độc lâp cho nguy cơ xảy ra biến cố gộp (tử vong và tái nhập viện) trong 6 tháng theo dõi. Mặt khác, tình trạng khó thở NYHA>2 khi được hiệu chỉnh với các yếu tố trên chưa cho thấy mối liên quan có ý nghĩa thống kê ( $p>0,05)$.

Khi so sánh kết quả nghiên cứu của chúng tôi với một số nghiên cứu khác trên thế giới, chúng tôi nhận thấy có sự tương đông. Hầu hết các nghiên cứu cho rằng $\mathrm{KCĐB6P}<300 \mathrm{~m}$ là yếu tố tiên lượng độc lập đối với biến cố gộp tử vong và tái nhập viện ở bệnh nhân suy tim mạn tính ${ }^{6-8}$.

\section{KẾT LUÂ̂N}

Nghiên cứu đã cho thấybên cạnh các yếu tố tiên lượng kinh điển (tăng nồng độ NT- proBNP và giảm EF), thì NPĐB6P với KCĐB6P < 290m cũng là một yếu tố tiên lượng độc lập cho nguy cơ xảy ra biến cố gộp (tử vong và tái nhập viện) ởcác bệnh nhân suy tim phân số tống máu thất trái giảm khi theo dõi trong vòng 6 tháng.

TÀI LIỆU THAM KHẢO

1. Bui, A. L., Horwich, T. B. \& Fonarow, G.
C(2011)."Epidemiology and risk profile of heart failure". Nat. Rev. Cardiol. 8, 30-41 (2011).

2. Shah KS, Xu H, Matsouaka RA, et al (2017). "Heart failure with preserved, borderline, and reduced ejection fraction: 5-year outcomes".J Am Coll Cardiol. 2017; 70(20):2476-2486.

3. Reyes, E.B., et al (2016)."Heart failure across Asia: Same healthcare burden but differences in organization of care". International Journal of Cardiology, 2016. 223: p. 163-167.

4. Ponikowski $P$, Voors AA, Anker SD, et al (2016)." 2016ESC Guidelines for the diagnosis and treatment of acute and chronic heart failure: The Task Force for the diagnosis and treatment of acute and chronic heart failure of the European Society of Cardiology (ESC)". Developed with the special contribution of the Heart Failure Association (HFA) of the ESC. Eur Heart J. 2016 Jul 14

5. Uszko-Lencer NHMK, Mesquita R, Janssen $E$, et al (2017). "Reliability, construct validity and determinants of 6-minute walk test performance in patients with chronic heart failure". International Journal of Cardiology. 2017;240:285-290.

6. Forman DE, Fleg JL, Kitzman DW, et al (2012). "6-Min Walk Test Provides Prognostic Utility Comparable to Cardiopulmonary Exercise Testing in Ambulatory Outpatients With Systolic Heart Failure". Journal of the American College of Cardiology. 2012;60(25):2653-2661.

7. Guazzi M, Dickstein $K$, Vicenzi $M$, Arena $\mathbf{R}$ (2009). "Six-minute walk test and cardiopulmonary exercise testing in patients with chronic heart failure: a comparative analysis on clinical and prognostic insights". Circ Heart Fail. 2009;2(6):549-555.

8. Arslan S, Erol MK, Gundogdu F, et al (2007). "Prognostic value of 6-minute walk test in stable outpatients with heart failure".Tex Heart Inst J. 2007;34(2):166-169. 53.

\title{
ĐÁNH GIÁ KẾT QUẢ SỚM BÓC NHÂN PHÌ ĐẠI LÀNH TÍNH TUYẾN TIỀN LIỆT BẰNG HOLMIUM LASER QUA ĐƯỜNG NIỆU ĐẠO TẠI BỆNH VIỆN HỮU NGHI VIỆT ĐỨC
}

\section{TÓM TẮT}

Mục đích: Trong nghiên cứu này chúng tôi áp dung kỹ thuật bóc nhân phì đại lành tính tuyến tiền liệt nội soi qua đường niệu đạo theo phương pháp 1 khối cải tiến và đánh giá tính an toàn, kết quả sớm của phẫu thuật bóc nhân phì đại lành tính tuyến tiền

\footnotetext{
${ }^{1}$ Bệnh viện Hữu nghị Đa khoa Nghệ An ${ }^{2}$ Trường Đại học Y Hà Nội

Chịu trách nhiệm chính: Võ Văn Chung

Email: vovanchung93@gmail.com

Ngày nhận bài: 15.9.2021

Ngày phản biên khoa họ: 15.11.2021

Ngày duyệt bài: 22.11.2021
}

\section{Võ Văn Chung ${ }^{1}$, Đỗ Trường Thành ${ }^{2}$}

liệt theo phương pháp bóc nhân một khối. Phương pháp nghiên cứu: chúng tôi nghiên cứu tiến cứu trên 38 bênh nhân rối loạn tiểu tiện do u phì đai lành tính tuyến tiền liệt, được phẫu thuật bóc nhân phì đại bằng laser Holmium tư tháng 4/2020 đến tháng 8/2020. Kỹ thuật phẫu thuật bóc nhân phì đại 1 khối cải tiến được thực hiện bằng 2 đường rạch ở vị trí $12 \mathrm{~h}$ và $6 \mathrm{~h}$. Trong mổ chúng tôi đánh giá thời gian bóc nhân phì đại, thời gian say nhỏ và lấy bệnh phẩm ra ngoài. Lượng máu mất, các tai biến trong mổ. Các thông số sau mổ bao gồm: thời gian đặt ống thông niệu đaao, thời gian nằm viện. Tình trạng tiểu tiện sau mổ. Các biến chứng sau mổ được đánh giá theo phân độ của Clavien-Dindo. Bệnh nhẩn được đánh giá theo dổi ở thời điểm 3 tháng sau mổ. Kết quả: Có $38 \mathrm{TH}$ thực hiện HoLEP. Tuổi trung bình là $73.7 \pm 10.4$, có 
52.6\% bệnh nhân có bệnh lý nền kèm theo. 100\% bệnh nhân nhập viện với điểm IPSS ở mức độ nặng $\geq$ 20 điểm (trung bình trước mổ là 28.95) và $84.21 \%$ bệnh nhân đánh giá chất lượng cuộc sống ở mức khổ sở, không chịu được với điểm QoL $\geq 5$ điểm. Thể tích TTL đo được trên siêu âm trung bình là $75.97 \pm 27.65$ $\mathrm{ml}$. Thời gian phẫu thuật trung bình là $96.84 \pm 11.47$. Thời gian bóc u trung bình là $66.21 \pm$ 10.81. Mức chênh lệch HGB trước và sau mổ không đáng kể 1.09 $\pm 0.78 \mathrm{~g} / \mathrm{dL}$, tuy nhiên biến chứng sau mổ cao nhất là truyền máu sau mổ với $10.53 \%$ do đa số các trường hợp này có mức HGB trước mổ thấp. Thang điểm quốc tể về triệu chứng TTL (IPSS) cải thiện sau mổ 1, 3, 6 tháng xuống lần lượt là 6.16, 4.39, 3.61. 100\% bệnh nhân đánh giá chất lượng cuộc sông sau 6 tháng phẫu thuật ở mưức tốt với điểm QoL trung bình là 1.24. Kết luân: Phẫu thuất bóc nhân phì đai lành tính TTL HoLEP ở bệnh nhân U phì đại lành tính TTL là phẫu thuât an toàn dễ thực hiện và có hiêu quả với moi kích thước của u phì đại lành tính tuyến tiền liệt.

Tư Khóa: Bóc nhân phì đại lành tính tuyến tiền liệt, Holmium laser, HoLEP

\section{SUMMARY}

\section{EVALUATION OF RESULTS EARLY SURGERY} TO REMOVE BENIGN PROSTATIC HYPERTROPHY BY HOLMIUM LASER THROUGH URETHRAL ENDOSCOPY AT VIETNAM - GERMANY

\section{FRIENDSHIP HOSPITAL}

Objectives:In this study, we apply the technique of enucleation modified en block of benign prostate hyperplasia by Holmium laser and evaluate the early results of this surgery. Materials and Methods: We evaluated on 38 patients with urinary disorders due to benign prostatic hyperplasia, undergoing surgery to remove hypertrophic benign prostate by Holmium laser from april 2020 to August 2020. The en bloc method enucleation modified was performed by 2 incisions at 12 o'clock and 6 o'clock.Perioperative we assessed the time of enucleation, the time of morcellation to take the specimens out. The amount of blood lost during surgery, bleeding complications. Postoperative parameters include: time of urethral catheterization, length of hospital stay. Functional outcomes: Qmax and IPSS at 3 month postoperative. Short term complications including clot retention (blood clot retention in the bladder), blood transfusion, urinary tract infection, recatheterisation, and incontinence.Clavien-Dindo classification complications, and continence status were assessed. Patients were assessed for follow-up after surgery for 3 month. Result: The average age is $73.7 \pm 10.4$. 100 percents of patients was admitted to the hospital with a severe IPSS score of $\geq 20$ points and 84.2 percents of patients had miserable and intolerable quality of life with a QoL score $\geq 5$ points. The average size of $\mathrm{PBH}$ measured on ultrasound was $75.97 \pm 27.65 \mathrm{ml}$. The average surgery time was $96.84 \pm 11.47$. The mean removal time was $66.21 \pm$ 10.81. The difference in HGB before and after surgery was not significant $(1.09 \pm 0.78 \mathrm{~g} / \mathrm{dL})$, however, the highest postoperative complication was blood transfusion after surgery with $10.5 \%$. Most of these cases had low preoperative HGB level. The international score of prostate symptoms (IPSS) mean improvement after surgery 1, 3, 6 months reduced from 28.95 to $6.16,4.39,3.61$, respectively. $100 \%$ of patients rated the quality of life after 6 months of surgery as good with an average QoL score of 1.24. Conclusion: The procedure of enucleation of benign prostatic hyperplasia with Holmium laser is safe and effective surgery for all sizes of benign prostatic hyperplasia.

Key words: benign prostatic hyperplasia, holmium laser, enucleation.

\section{I. ĐẶT VẤN ĐỀ}

Phương pháp bóc nhân phì đại tuyến tiền liệt bằng laser Holmium (HoLEP) lần đầu tiên được giới thiệu từ khoảng 20 năm trước bởi Fraundorfer và Gilling. Kể từ đó, đã có nhiều nghiên cứu chứng minh rằng HoLEP mang lại kết quả thuận lợi hơn so với phẩu thuật cắt bỏ tuyến tiền liệt qua niệu đạo truyền thống (TUR-P) cho nam giới với các triệu chứng đường tiểu dưới (LUTS) và tăng sản lành tính tuyến tiền liêt $(\mathrm{BPH})$, cả về thời gian đặt ông thông sau phấu thuật, thời gian nằm viện và chảy máu trong mổ. Tuy nhiên phương pháp bóc nhân phì đại lại được thực hiên theo nhiều cách khác nhau. Trên thực hành lẩm sàng chúng tôi thực hiện bóc nhân phì đại 1 khối cải tiến bằng hai đường rạch ở vị trí $6 \mathrm{~h}$ và $12 \mathrm{~h}$ và chúng tôi đánh giá kết quả sớm trên những bệnh nhân đã được thực hiện phương pháp này.

\section{II. ĐỐI TƯỢNG VÀ PHƯƠNG PHÁP NGHIÊN CỨU}

Đối tượng nghiên cứu:Nghiên cứu thực hiện tại bệnh viện Hữu Nghị Việt Đức từ tháng $4 / 2020$ đến tháng $8 / 2021$

\section{Tiêu chuẩn lựa chọn bệnh nhân:}

1.Lựa chọn bệnh nhân: - Bệnh nhân trên 50 tuổi, có rối loạn tiểu tiện do u phì đại lành tính TTL với điểm IPSS $\geq 20$. Bệnh nhân bí tiểu do u phì đại lành tính TTL. PSA $\leq 10 \mathrm{ng} / \mathrm{ml}$.

- Khối lượng TTL xác định qua siêu âm từ $30 \mathrm{~g}$ trở lên, mật độ u đồng nhất.

- Lượng nước tiểu tồn dư sau đi tiểu $\geq 100 \mathrm{ml}$

- Kết quả giải phẫu bênh sau mổ khẳng định u phì đại lành tính TTL, hoăc sinh thiết trước mổ khẳng định u phì đại lành tính tuyến tiền liệt

- Bệnh nhân đồng ý tham gia nghiên cứu

\section{Nghiên cứu được thông qua hội đồng}

khoa học bệnh viện Hữu Nghị Việt Đức, các thông tin phục phụ cho nghiên cứu khoa học, mang lại lợi ích cho người bệnh.

Phương pháp nghiên cứu: Nghiên cứu tiến cứu mô tả hàng loạt trường hợp.

Phương pháp thực hiện: Bệnh nhân có chỉ 
định phẫu thuật HoLEP được thăm khám lâm sàng, đánh giá điểm IPSS, QoL, làm các xét nghiệm cần thiết cho phấu thuật, giải thích và cam kết đồng ý phẫu thuật. Ghi nhận các chỉ số cần thiết của nghiên cứu như xét nghiệm công thức máu, sinh hóa máu, chỉ số PSA, sinh hóa nước tiểu, siêu âm, sinh thiết tuyến tiền liệt khi PSA >10ng/ml, phương pháp vô cảm, thời gian phẫu thuật, thời gian bóc $U$, tai biến và biến chứng trong và sau mổ, khí máu ngay sau mổ, theo dõi kết quả sau PT 1, 3, 6 tháng.

\section{Quy trình kỹ thuật trong mổ:}

Tư thế bệnh nhân: $\mathrm{BN}$ nằm theo tư thế sản phụ khoa trên bàn mổ tiết niệu có thể điều chỉnh.

*Vô cảm; Gây tê tủy sống, hoặc gây mê toàn thân.

- Bước 1: Đặt ống nội soi niệu đạo, bàng quang quan sát hai lỗ niệu quản. Quan sát u phì đại tuyến tiền liệt, ụ núi. Đánh giá sơ bộ kích thước u phì đại và thùy giữa, hai thùy bên.

- Bước 2: Dùng laser bóc niêm mạc niệu đạo tuyến tiền liệt ở vị trí $6 h$, ngay trên ụ núi, bộc lộ nhân phì đại thùy giữa đồng thời tách rời nhân phì đại phải và trái ngay trên ụ núi khỏi vỏ TTL.

- Bước 3: Thực hiện tách nhân phì đại ở vị trí 12h, bắt đầu từ phía cổ bàng quang, tách rời nhân phì đại bên phải, bên trái dần từ cổ bàng quang tới phía trên ụ núi khỏi vỏ tuyến tiền liệt và chú ý phối hợp với đường bóc ở vị trí 6 h.

- Bước 4: Bóc hoàn toàn thùy bên trái dần từ $12 \mathrm{~h}$ về $6 \mathrm{~h}$ và dần từ phía ụ núi về cổ bàng quang.

- Bước 5: Bóc hoàn toàn thùy bên phải dần từ $12 \mathrm{~h}$ về $6 \mathrm{~h}$ và dần từ phía ụ núi về cổ bàng quang.

- Bước 6: bóc rời hoàn toàn khối nhân phì đại từ trái sang phải theo trình tự từ cổ bàng quang về phía ụ núi, rồi lại từ ụ núi về phái cổ bàng quang và cuối cùng đẩy toàn bộ nhân phì đại vào lòng bàng quang.

- Bước 7: Kiểm tra lại toàn bộ diện bóc u và cầm máu kỹ cho tới khi nước rửa trong tối đa có thể. Nếu còn sót những nhân nhỏ nào thì bóc nó một cách dễ dàng.

- Bước 8: Sử dụng tay cắt truyền thống cắt nốt phần niêm mạc $u$ còn sót lại quanh ụ núi và cổ bàng quan

- Bước 9: Dùng dụng cụ say u, để lấy bệnh phẩm ra ngoài.

- Bước 10: Đặt ống thông 3 chạc niệu đạo, rửa bàng quang liên tục.

Ngay sau mổ bệnh nhân được làm xét nghiệm công thức máu và sinh hóa máu, điện giải đồ.

Thu thập, xử lý số liệu: Thu thập và xử lý số liệu bàng ứng dụng phần mềm thống kê SPSS phiên bản 20.0 .

\section{KẾT QUẢ NGHIÊN CỨU}

Nghiên cứu trên 38 trường hợp, tuổi trung bình là $73.7 \pm 10.4$ tuổi. Nhỏ tuổi nhất là 54 tuổi, lớn nhất là 90 tuổi. Có $52.6 \%$ trường hợp có bệnh lý nền kèm theo.

Tất cả bệnh nhân vào viện với triệu chứng lâm sàng nặng có điểm IPSS > 20 điểm trong đó triệu chứng chiếm tỉ lệ nhiều nhất là tiểu đêm với $78.9 \%$. Có $84.21 \%$ trường hợp đánh giá mức sống khó khăn, không chịu được với điểm QoL $\geq$ 5 điểm. Không có trường hợp bị rối loạn đông máu hay suy giảm chức năng thận nặng. Chỉ số PSA trung bình trước phẫu thuật là $10.25 \pm$ $9.72 \mathrm{ng} / \mathrm{mL}$. Thể tích trung bình tuyến tiền liệt là $75.97 \pm 27.65 \mathrm{ml}$, trong đó lớn nhất là $160 \mathrm{ml}$, nhỏ nhất là $40 \mathrm{ml}$.

2. Về kết quả của phẫu thuật bóc u phì đại lành tính tuyến tiến liệt băng Holmium laser qua niệu đạo: Thời gian phẫu thuật trung bình của 38 TH là $96.84 \pm 11.47$ phút, thời gian bóc nhân trung bình là $66.21 \pm 10.81$ phút. HGB giảm trung bình sau PT là $1.1 \pm 0.78 \mathrm{~g} / \mathrm{dL}$, Natri máu giảm trung bình là $2.81 \pm 2.7 \mathrm{mmol} / \mathrm{L}$. Biến chứng chiếm tỷ lệ cao nhất là biến chứng cần truyền máu sau PT với $10.53 \%$, ngoài ra còn một số biến chứng khác như bí tiểu sau rút thồng tiểu, nhiễm trùng đều chiếm $2.63 \%$, tiểu rỉ chiếm $7.89 \%$. tất cả các biến chứng trên đều được điều trị cải thiện tốt trước khi ra viện. Thời gian đặt thông tiểu trung bình sau PT là $4.16 \pm$ 0.89 ngày. Thời gian nằm viện trung bình sau PT là $5.84 \pm 1.87$ ngày. $100 \%$ các trường hợp có kết quả giải phẫu bệnh sau PT là "quá sản lành tính tuyến tiền liệt".

Bảng 1: Cải thiện điểm IPSS và QoL sau phẫu thuật

\begin{tabular}{|c|c|c|}
\hline Thời điểm & $\begin{array}{c}\text { Giá trị trung } \\
\text { bình }\end{array} \overline{\mathbf{X}} \mathbf{\pm}$ SD & $\begin{array}{c}\text { P (so với } \\
\text { trước PT) }\end{array}$ \\
\hline \multicolumn{3}{|c|}{ Điếm IPSS } \\
\hline Trước PT & $28.95 \pm 4.51$ & \\
\hline Sau PT 1 tháng & $6.16 \pm 2.31$ & $0<0.05$ \\
\hline Sau PT 3 tháng & $4.39 \pm 1.73$ & $0<0.05$ \\
\hline Sau PT 6 tháng & $3.61 \pm 1.31$ & $0<0.05$ \\
\hline \multicolumn{3}{|c|}{ Điếm QoL } \\
\hline Trước PT & $5,29 \pm 0.72$ & \\
\hline Sau PT 1 tháng & $2.21 \pm 0.91$ & $0.014<0.05$ \\
\hline Sau PT 3 tháng & $1.76 \pm 0.79$ & $0.028<0.05$ \\
\hline Sau PT 6 tháng & $1.24 \pm 0.59$ & $0.013<0.05$ \\
\hline
\end{tabular}

\section{BÀN LUÂ̂N}

1. Đặc điểm lâm sàng và cận lâm sàng của bệnh nhân bị u phì đại lành tính tuyến tiên liệt: Bệnh lý U phì đại lành tính TTL là bệnh lý phổ biến gây ảnh hưởng nhiều đến cuộc sống 
của bệnh nhân đặc biệt ở những người lớn tuổi. Trong nghiên cứu của chúng tôi độ tuổi trung bình là $73.7 \pm 10.4$ tuổi trong đó nhóm tuổi chiếm đa số là 60 - 80 tuổi (60.5\%). Thống kê này cũng tương đồng với một số nghiên cứu của các tác giả khác như: Nguyễn Tế Kha ${ }^{1}$ (tuổi trung bình $72.95 \pm 7.84$ ); tác giả Nguyễn Ngọc Thái (tuổi trung bình $72.17 \pm 9.55$ ), Dương Hoàng Lân ${ }^{3}$ (tuổi trung bình là $72.21 \pm 10.39$ ). Đa số bệnh nhân đến khám có triệu chứng đường tiểu nặng nề với điểm IPSS trung bình là $28.95 \pm 4.51$ điểm, và đánh giá chất lượng cuộc sống ở mức khó khăn, không chịu được với điểm QoL trung bình là $5,29 \pm 0.72$ điểm. Tỷ lệ bệnh nhân bí tiểu chiếm $13.2 \%$, thông kê này thấp hơn so với một số nghiên cứu trước đó của các tác giả Trần Ngọc Sinh với số trường hợp bí tiểu chiếm $81.44 \%{ }^{4}$ và tác giả Lý Hoàng Phong là 54.6\%. ${ }^{5}$

Cận lâm sàng được làm đây đủ với mục đích chẩn đoán bệnh cũng như để theo dõi và đánh giá kết quả phẫu thuật. Trong nghiên cứu của chúng tôi, sự chênh lệch HGB trước và sau phẫu thuật là không đáng kể với chỉ số trung bình là $1.09 \pm 0.78 \mathrm{~g} / \mathrm{dL}$, tuy nhiên tỉ lệ biến chứng truyền máu sau mổ vẫn chiếm nhiều nhất với $10.53 \%$, điều này có thể giải thích là do HGB của bệnh nhân trước mổ với nhiều bệnh lý nền kèm theo đã ở mức thấp từ $90-110 \mathrm{~g} / \mathrm{L}$ do đó dù trong quá trình phấu thuật đã kiểm soát chảy máu trong mổ kỹ lưỡng hởn nhưng sau mổ vẫn cần truyền máu nhằm ổn định tuần hoàn và tránh tai biến về huyết động. Hình ảnh siêu âm là một công cụ đắc lực trong chẩn đoán cũng như theo dỗi bệnh trước và sau PT, trong nghiên cứu của chúng tôi thể tích trung bình TTL là $75.97 \pm 27.65 \mathrm{ml}$ trong đó lớn nhất là $160 \mathrm{ml}$, nhỏ nhất là $40 \mathrm{ml}$, chỉ số này cao hơn so với nghiên cứu của một số tác giải trước đó như: tác giả Trân Ngọc Định $(65,1 \mathrm{gram}){ }^{6}$ Karakose (64,5gram) ${ }^{7}$ Đỗ Ngọc Thể $(48,6 \mathrm{gram}){ }^{8}$ Bên canhh đó chỉ số PSA trong nghiên cứu này trung bình là $10.25 \pm 9.72 \mathrm{ng} / \mathrm{mL}$, được xem là nằm ở mức cao so với chỉ số sinh lý thông thường của bệnh lý u phì đại lành tính $T T L$, tuy nhiên kết quả sinh thiết trước và sau mổ của $100 \%$ trường hợp đều cho kết quả lành tính.

2. Kết quả gân điêu trị bóc u phì đại lành tính tuyến tiên liệt bằng holmium laser qua nội soi niệu đạo: Phẫu thuật bóc nhân phì đại lành tính tuyến tiên liệt là một phương pháp có tỉ lệ thành công cao, cải thiện triệu chứng lâm sàng rõ rệt, đã được nhiều cơ sở trong và ngoài nước thực hiện và cải tiến từ năm 1998 với phương pháp ba thùy cổ điển của Gilling cùng cộng sự đến nay với phương pháp bóc nhân 1 khối (En bloc) của nhiều tác giả nước ngoài như: Kim cùng cộng sự năm 2015, Miernik và Schoeb năm 2019. ${ }^{9}$ Trong nghiên cứu của chúng tôi chì có 1 trường hợp có tai biến trong mổ là tổn thương niêm mạc thành bàng quang tuy nhiên bệnh nhân phục hồi tốt trước khi ra viên. Tỷ lệ truyền biến chứng truyền máu sau phẫu thuật trong nghiên cứu cao hơn so với đa số các nghiển cứu khác, nguyên nhân được giải thích là do cả 4 TH có biến chứng trên đều có mức HGB trước mổ ở mức thấp từ $90-110 \mathrm{~g} / \mathrm{L}$, do đó dù trong phẫu thuật đã cầm máu kỹ lưỡng và sau phẫu thuật huyết động ổn định nhưng lượng HGB vẫn thẩp dưới $90 \mathrm{~g} / \mathrm{L}$ nên truyền máu là cần thiết.

Bảng 4.1. Biến chứng sau phẫu thuật theo nhiều tác giả.

\begin{tabular}{|c|c|c|c|c|}
\hline $\begin{array}{l}\text { Tác giả } \\
\text { (năm), } \\
\text { số BN }\end{array}$ & $\begin{array}{l}\text { Bí tiếu } \\
\text { Sau rút } \\
\text { thông } \\
\text { nđ }(\%)\end{array}$ & $\begin{array}{c}\text { Tiểu } \\
\text { không } \\
\text { ks tam } \\
\text { thời } \\
(\%)\end{array}$ & $\begin{array}{c}\text { Nhiễm } \\
\text { khuẩn } \\
\text { đướng } \\
\text { tiết } \\
\text { niệu(\%) }\end{array}$ & $\begin{array}{c}\text { Chảy } \\
\text { máu } \\
\text { cần } \\
\text { truyền } \\
\text { máu } \\
(\%)\end{array}$ \\
\hline $\begin{array}{l}\text { Moody (2000) } \\
61 \mathrm{BN}\end{array}$ & 3.6 & 4.8 & 4.8 & 0 \\
\hline $\begin{array}{c}\text { Gilling (2000) } \\
\text { 40BN }\end{array}$ & 13.2 & 8.6 & 3.6 & 0 \\
\hline $\begin{array}{c}\text { Kuntz (2002) } \\
60 B N\end{array}$ & 8.7 & 4.8 & 2.4 & 0 \\
\hline \begin{tabular}{|c|} 
Elmansy (2012) \\
$949 \mathrm{BN}$
\end{tabular} & 5.6 & 7.2 & 4.1 & 0.4 \\
\hline $\begin{array}{c}\text { Naspro (2006) } \\
41 \mathrm{BN}\end{array}$ & 12.1 & 16.1 & 2.7 & 0 \\
\hline $\begin{array}{c}\text { Krambeck(2010) } \\
1065 \mathrm{BN}\end{array}$ & 13.8 & 12.5 & 4.2 & 0 \\
\hline $\begin{array}{l}\text { Nghiên cứu của } \\
\text { chúng tôi } 38 \text { BN }\end{array}$ & 2.63 & 7.89 & 2.63 & 10.53 \\
\hline
\end{tabular}

Sự cải thiên triêu chứng lâm sàng và chất lượng cuộc sống của bênh nhân là hoàn toàn rõ rệt. 6 tháng sau phẫu thuật $100 \%$ bệnh nhân không còn các triệu chứng khó chịu về đường tiểu dưới. Điểm IPSS trung bình trước PT là $28.95 \pm 4.51$ điểm. sau PT 1 tháng, 3 tháng và 6 tháng lần lượt là $6.16 \pm 2.31 ; 4.39 \pm 1.73 ; 3.61$ \pm 1.31 . Sự khác biệt này trước và sau PT có ý nghĩa thống kê $(p<0.05)$, điều đó cho thây sự cải thiện rõ rệt về lâm sàng trước và sau PT (Paired Samples Test). Một số nghiên cứu khác của các tác giải nước ngoài cũng chứng minh cho sư cải thiện rõ rệt này như: Elmansy và cộng sự điểm IPSS trước mổ trung bình 22,4 \pm 4,6. Điểm IPSS trung bình tái khám sau 1 tháng, 3 tháng, 6 tháng lần lượt là $9,3 \pm 6,1 ; 5,1 \pm 3,9$; $4,4 \pm 4,8{ }^{8}$ Theo tác giả Naspro $R$ (năm 2006, 41TH) điểm IPSS trước mổ trung bình 20,1 \pm 
5,8 . Điểm IPSS trung bình tái khám sau 1 tháng, 3 tháng, 6 tháng lần lượt là $6,9 \pm 4,2 ; 3,9 \pm 2,9$; $8,4 \pm 5,9$. $100 \%$ bệnh nhân đánh giá chất lượng cuộc sống tốt và rất tốt 6 tháng sau PT qua thang điểm QoL. Điểm QoL trung bình trước PT là $5.29 \pm 0.72$ và sau PT 1 tháng, 3 tháng, 6 tháng lân lượt là $2.21 \pm 0.91 ; 1.76 \pm 0.79 ; 1.24$ \pm 0.59. Sự khác biệt này có ý nghĩ thống kê cũng cho thây sự cải thiện tốt về chất lượng cuộc sônng của bệnh nhân. Một số tác giả khác cũng có nghiên cứu cho thây quan điểm tương đồng như: tác giả Gilling PJ (năm 2000, 40TH) sự điểm QoL trước mổ trung bình 4,8 $\pm 1,1$. Điểm QoL trung bình tái khám sau 1 tháng, 3 tháng, 6 tháng lần lượt là $2,7 \pm 0,4 ; 1,8 \pm 0,4$; $1,6 \pm 0,3 .^{9}$ tác giả Naspro R (năm 2006, 41TH) điểm QoL trước mổ trung bình 4,07 \pm 0,93. Điểm QoL trung bình tái khám sau 1 tháng, 3 tháng, 6 tháng lân lượt là $1,4 \pm 1,4 ; 1,0 \pm 0,8$; $1,7 \pm 0,94^{9}$.

\section{KẾT LUÂ̂N}

Phẫu thuật bóc u phì đại lành tính tuyến tiền liệt bằng Holmium laser qua đường niệu đạo là phương pháp điều trị an toàn và hiệu quả, cải thiện tốt triệu chứng cũng như chất lượng cuộc sống của bệnh nhân.

\section{TÀI LIẸU THAM KHẢO}

1. Nguyễn Tế Kha, (2018), Vai trò LASER Thulium trong điều trị ngoại khoa tăng sinh lành tính tuyến tiền liệt, Luân văn Tiến sĩ Y học, Đại học Y dược thành phố Hồ Chí Minh

2. Nguyển Ngoc Thái, (2012), "Đánh giá sư cải thiện triệu chứng đướng tiết niệu dưới sau cắt đốt nội soi tăng sinh lành tính tuyến tiền liệt với kỹ thuật Laser Thulium", Luân văn Thạc sĩ Y học, Đại học Y dược Thành phố Hồ Chí Minh, pp.

3. Dương Hoàng Lân, (2015), "Đánh giá kết quả của cắt đốt nội soi bằng điện lưỡng cực trong tăng sinh lành tính tuyến tiền liệt", Luận văn Thạc sĩ Y học, Đại học Y dược thành phố Hồ Chí Minh, pp.

4. Trân Ngọc Sinh, (2001), "Chỉ đinh điều trị cắt đốt nội soi trong bế tắc đường tiết niệu dưới do bướu lành tiền liệt tuyến", luận án tiến sĩ khoa học Y Dước, (Đai hoc Y Dước TPHCM.), pp.

5. Lý Hoàng Phong, (2007), "Tai biến và biến chứng sớm sau cắt đốt nội soi bướu lành tuyến tiền liệt, Luận văn thạc sĩ y khoa, " Đại học Y Dược TP HCM, pp.

6. Trân Ngọc Định (2019). Kết quả phẫu thuật nôi soi qua niệu đạo điêu trị phì đại tuyến tiền liệt bằng điện lưỡng cực, Luận văn Thạc sỹ Y học, Đại học Y Hà Nội.

7. Karakose A., Atesci Y.Z. (2014). BiVap Saline Vaporization of the Prostate in Men with Benign Prostatic Hyperplasia: Our Clinical Experience. Urology, 83(3), pp.570-575.

8. Đố Ngọc Thê (2018). Nghiên cứu ứng dụng và đánh giá kết quả điều trị bệnh tăng sinh lành tính tuyến tiên liệt bằng phương pháp bốc hơi lưỡng cực qua nội soi niệu đạo, Luận án Tiến sỹ Y học, Học viên Quân Y.

9. Fraundorfer MR, Gilling PJ. Holmium: YAG laser enucleation of the prostate combined with mechanical morcellation: preliminary results. Eur Urol 1998;33:69-72.

\section{TAO HÌNH THÀNH NGỰC ĐIỀU TRI VIÊM LOÉT DO XẠ TRI BẲNG VẠT DA CO' LƯNG RộNG: NHÂN MộT TRƯỜ'NG HợP}

\section{TÓM TẮT}

Đặt vấn đê: Viêm loét thành ngực sau xạ trị là một biến chứng ít gặp, gây ảnh hưởng nhiêuu tới thẩm mỹ cũng như chức năng cho bệnh nhân ung thư vú. Đây cũng là một thách thức không nhỏ cho các nhà lâm sàng hiện nay. Chúng tôi mô tả một trường hợp viêm loét thành ngực ở bệnh nhân ung thư vú sau xạ trị được điêuu trị tại Khoa Ngoại vú, Bệnh viện K. Ca lâm sàng: Bệnh nhhân nữ 64 tuổi, chẩn đoán ung thư vú phải, được phấu thuật cắt tuyến vú triệt căn biến đổi, điêu trị hóa chất và tia xạ bô trợ lần 1 năm 2001;

\section{${ }^{1}$ Bênh viện $K$}

Chịu trách nhiệm chính: Lê Hồng Quang

Email: bslequang@gmail.com

Ngày nhận bài: 16.9.2021

Ngày phản biên khoa họ: 12.11.2021

Ngày duyệt bài: 23.11.2021

\section{Lê Hồng Quang1}

tia xạ lần 2 năm 2004 do tái phát thành ngực phải, năm 2020 bệnh nhân xuất hiện viêm loét thành ngực và được phấu thuật tạo hình thành ngực sử dụng vạt da - cỡ lưng rộng che phủ. Quá trình phẫu thuật và hậu phẫu an toàn, bệnh nhân được xuất viện sau mổ 10 ngày. rộng

Tư khóa: viêm loét thành ngực, vạt da cơ lưng

\section{SUMMARY \\ CHEST WALL RECONSTRUCTION WITH LATISSIMUS DORSI FLAP FOR CHRONIC RADIATION-INDUCED ULCER PATIENT: A CASE REPORT}

Introduction: Chronic radiation-induced ulcer is a rare complication that greatly affects the aesthetics and function of breast cancer patients. This is also a big challenge for clinicians today. We describe a case of chest wall ulcer in a breast cancer patient after 